\title{
Clinical Pediatrics
}

\section{Reported Sports Participation, Race, Sex, Ethnicity, and Obesity in US Adolescents from NHANES Physical Activity (PAQ_D)}

\begin{tabular}{|r|l|}
\hline Journal: & Clinical Pediatrics \\
\hline Manuscript ID: & Draft \\
\hline Manuscript Type: & Article \\
\hline Complete List of Authors: & $\begin{array}{l}\text { Turner, Robert; University of Maryland, College Park, African American } \\
\text { Studies Department; University of North Carolina, Pediatrics } \\
\text { Perrin, Eliana; The University of North Carolina at Chapel Hill School of } \\
\text { Medicine, Division of General Pediatrics and Adolescent Medicine; } \\
\text { University of North Carolina at Chapel Hill School of Medicine, Department } \\
\text { of Internal Medicine, Division of General Medicine; University of North } \\
\text { Carolina at Chapel Hill School of Medicine, Pediatrics } \\
\text { Coyne-Beasley, Tamera; University of North Carolina at Chapel Hill School } \\
\text { of Medicine, Department of Internal Medicine, Division of General Medicine; } \\
\text { The University of North Carolina at Chapel Hill School of Medicine, Division } \\
\text { of General Pediatrics and Adolescent Medicine; University of North Carolina } \\
\text { at Chapel Hill School of Medicine, Pediatrics } \\
\text { Peterson, Camilla; Center for Science in the Public Interest, } \\
\text { Skinner, Asheley; University of North Carolina at Chapel Hill School of } \\
\text { Medicine, Pediatrics }\end{array}$ \\
\hline Specialties: & \begin{tabular}{l} 
Adolescent medicine, General pediatrics \\
\hline
\end{tabular} \\
\hline
\end{tabular}

\section{SCHOLARONE" Manuscripts}


Reported Sports Participation, Race, Sex, Ethnicity, and Obesity in US Adolescents from NHANES Physical Activity (PAQ_D)

Short Title: Adolescent Sport Participation, Sex, Race and Obesity

Abbreviations: BMI: Body Mass Index; PA: Physical Activity

Key Words: Sports, athletes, obesity, adolescents

Disclosures: The authors have no conflicts of interest to disclose.

Implications and Contribution: A greater proportion of adolescent males that self-report leisure time sport participation are healthy weight than females. We are unaware of reasons why differences in obesity among adolescent-athletes persist along gender lines. Future research will benefit from updated nationally represented survey data on adolescent physical activity or recreational and organized sport participation. 


\section{Introduction}

Adolescent obesity is a major public health problem in the United States (US), with prevalence rates disproportionately high among certain youth populations. ${ }^{1,2}$ Non-Hispanic black and Hispanic children and adolescents are consistently more likely to be obese (BMI $\geq 95 \%)$ compared with non-Hispanic white youth. ${ }^{1}$ This pattern is seen in both adolescent males (Hispanic 26.5\%, non-Hispanic black 22.6\% and non-Hispanic white 17.5\%) and females (Hispanic 19.8\%, non-Hispanic black 24.8\% and non-Hispanic white 14.7\%) aged 12-19 years. ${ }^{2}$ Obesity prevalence is overall significantly higher among males $(16.1 \%)$ than among females (11.7\%), although this difference by sex is not significant in Hispanic or non-Hispanic black children and adolescents. ${ }^{1}$

The lack of daily-recommended levels of adolescent physical activity, particularly among girls and members of ethnic populations has been. ${ }^{3-5}$ A comprehensive review of 108 studies revealed that ethnic minority children were as active as non-Hispanic whites; however, nonHispanic whites were more physically active as adolescents than other ethnic groups. ${ }^{6}$ Despite the health benefits of physical activity (PA), levels of inactivity are increasing among all youth over time. ${ }^{7}$ This trend is disturbing because youth PA is a predictor of sport participation and physical fitness activities during early adulthood. ${ }^{8}$ While youth from all backgrounds generally fail to meet national physical activity standards, low-income adolescents are less likely to adhere to these guidelines than their counterparts. 9,10

Understanding the impact of sports participation is essential since time for school physical education has decreased. Declines in sport participation are particularly significant among girls and boys during the transition from middle school to high school. ${ }^{11,12}$ Youth from higher income families are more likely to participate in out-of-school sport programs than youth 
from lower income families, leaving lower-income children particularly vulnerable to reduction in physical activity during school. ${ }^{13,14}$

Since physical inactivity and sedentary behavior are important risk factors for overweight and obesity in adolescence, considerable research attention is focused on creating policies that encourage physical activity and sport participation. ${ }^{15}$ Studies demonstrate that PA is positively associated with healthy weight, ${ }^{16}$ but the relationship between adolescent sport participation and obesity can be influenced by factors such as sociodemographic or the built environment, thus further research is necessary. ${ }^{4,17}$ Identifying associations between sport participation, PA, and patterns of obesity in adolescents is vital for the development of effective intervention strategies.

Research on sport participation that explored activity involvement among early adolescents includes team sports, school/community clubs, and organizational activities. Students involved in organized sports alone or in combination with other activities had significantly higher odds for exercise and healthy self-image. ${ }^{18}$ Although the benefits of sport participation are clear, ${ }^{19,20}$ few studies report on sports program participation by weight status for adolescents. Further, race, gender, and socio-economic status (SES) are rarely compared in sport participation studies of overweight and obese adolescents.

Evidence suggests preexisting overweight and obesity can discourage sports participation. ${ }^{21}$ For example, in a study of Australian adolescents, obese adolescents spent considerably less time than their normal-weight peers on team sports. ${ }^{22}$

Over the past three decades, scholars and public health officials have been challenged to understand the pronounced reduction in physical activity once children reach adolescence. ${ }^{23,24}$ Consequently, examining sport participation in this population is important, especially for adolescent males, a group whose obesity prevalence has steadily risen in recent years despite 
girls having reached a plateau. ${ }^{1}$ Notwithstanding these differences among girls and boys, National Health and Nutrition Examination Survey (NHANES) data over the past two decades show a dramatic increase in overweight and obesity prevalence across all population groups and a declining disparity of obesity across socioeconomic status (SES). This paper uses a nationally representative sample of 12-19 year old US adolescents to identify the relationship between obesity and leisure time sport participation, with a focus on differences by race, ethnicity, household income, and sex.

\section{Methods}

We used the NHANES from years 1999-2006; the activity portion of NHANES was discontinued in 2006. NHANES is a stratified, multistage probability sample of the civilian, noninstitutionalized US population. It includes an in-home questionnaire on several demographic and health-related topics, a computer-assisted interview, and an examination component consisting of a thorough physical exam including measured height and weight. ${ }^{25,26}$

We included 9,152 adolescents age 12-19 years. Because our goal was to identify adolescents in middle or high school whose activities were most likely to be related to leisure time sport participation we excluded 1,220 who were not enrolled in school (most were 18-19 years), 754 enrolled in college, and 513 in elementary school, for a final sample of 6,675 $(\mathrm{N}=$ 3,345 females and 3,330 males).

Children aged 12 years and older were eligible for the survey portion that collected data on their participation in specific activities. They self-reported all activities during the previous 30 days, the number of times they participated in the activity, the average duration, and average intensity. NHANES does not provide information on whether the activity was part of an organized sports team. So, we chose to identify adolescents who listed their most frequent activity as one of the five most popular sports for high school athletes. Although some 
adolescents may have been classified as participating in a sport that were not in a school-based team or organized program outside of school, we can capture differences based on their activities using the frequency described below.

To operationalize participation in leisure time sports, we first identified the most common sports according to the National Federation of State High School Associations, based on total number of participants. For girls these are running/track ${ }^{\mathrm{i}}$, basketball, volleyball, soccer, and softball; and for boys, football, running/track, basketball, baseball, and soccer. ${ }^{27}$ In order to create mutually exclusive categorizing, and to maximize the likelihood that reported physical activity was part of sport participation, we then assigned each individual to their "most frequent" common sport based on this hierarchy: (1) most amount of total time spent playing the sport, (2) most amount of vigorous time (defined in NHANES as "activity that causes heavy sweating or large increases in breathing or heart rate) spent playing the sport, and (3) number of unique occasions playing the sport. For the small number of adolescents who participated in two sports equally using all criteria ( $n=84,1.2 \%$ of the sample), we assigned their sport based on the overall popularity (e.g. a boy playing equal amounts of football and basketball was assigned to football). Adolescents not playing any of the five most common sports were categorized as "nonathlete/participant-in-other-activities," although it is possible they participated in another, less common, sport.

Adolescents were categorized as obese, overweight, or healthy weight based on the body mass index (BMI) percentiles and current CDC recommendations. ${ }^{28} \mathrm{We}$ used height and weight as measured during the examination component to calculate BMI percentile, using SAS code

\footnotetext{
i Athletes, coaches and scholars have long debated the merits of track and field as an individual or team sport. For our purposes, track/running is defined as a team sport since adolescent athletes generally participate on high school teams or organized track clubs.
} 
developed for that purpose. ${ }^{29}$ We classified adolescents in the $\geq 95^{\text {th }}$ percentile as obese. Because of concerns that athletes with relatively low adiposity may be considered overweight based on standard definitions, we compared those who were obese to the combined group of overweight and healthy weight adolescents. This is consistent with previous research that suggests participants in sports like American football and rugby tend to be more muscular, and thus a high BMI in these players does not necessarily reflect excessive adiposity. ${ }^{30}$

Race and ethnicity were categorized as non-Hispanic white, non-Hispanic black, Hispanic, or other race. Income was based on the percent of federal poverty level (FPL) of household income, from $<100 \%$ (most deprived) to $\geq 500 \%$ (most affluent). Grade was categorized as middle school (grades 6-8) and high school (grades 9-12).

We used adjusted Wald tests to examine the differences in the prevalence of obesity by organized sport participation for girls and boys separately. Because demographic factors such as race, ethnicity, and socioeconomic status likely affect sports participation, we used logistic regression analyses to examine the relationship between sport participation and obesity, controlling for child's school level, race/ethnicity, and income. All analyses were adjusted for the complex survey design of NHANES, as recommended by NCHS. ${ }^{27}$ Analyses were performed using the survey estimation routines in Stata 12.0 (College Station, TX). Because this study used only de-identified secondary data, it was deemed exempt from further review by the Institutional Review Board under federal regulation 45 CFR $\S 46.101(\mathrm{~b})$.

\section{Results}

Table 1 shows the demographic characteristics of the sample, stratified by sex. There were no significant differences by sex for race, income, grade, or age. For girls, $48 \%$ did not participate in the five most common female high school sports (Table 2a), whereas only $29 \%$ of boys did not participate in the five most common male high school sports (Table 2b). White girls 
(Table 2a) were more likely to play softball or volleyball, while black girls were more likely to play basketball, and Hispanic females more likely to play soccer. Higher-income girls were more likely to play softball, and lower-income girls were more likely to play basketball; participation did not otherwise differ by income. Leisure time sport participation declined universally for girls from middle school to high school.

Overall, black males (Table 2b) were more likely than white males to participate in one of the five most common high school sports, and were most likely to play basketball. White males were more likely to play baseball or run track, and Hispanic males were more likely to play soccer. The only differences in income were that higher-income boys were more likely to play baseball, while lower income boys were more likely to play basketball. Although leisure time sport participation declined from middle school to high school, football was the only sport for which this decline was statistically significant.

There were few differences in leisure time sport participation by weight for girls (Table 3). The prevalence of obesity did not differ overall among those who played organized sports compared to those who did not. There were also no differences by specific sport, except for running/track. Girls who reported they participate in running/track had a significantly lower prevalence of obesity than girls who did not participate in any leisure time sport activity. In contrast, the prevalence of obesity among male non-athletes/participants-in-other-activities was significantly higher than among boys who did. This finding was consistent for male baseball, basketball, running/track, and soccer athletes, although the prevalence of obesity among football players did not differ from non-athletes/participants-in-other-activities.

Multivariate models were consistent with the bivariate analyses. Girls were no more likely to be obese when playing any common sport, compared to female non- 
athletes/participants-in-other-activities. Girls participating in running/track were less likely to be obese, controlling for grade, race, and income. However, lower income was significantly associated with greater likelihood of being obese for girls ( $\mathrm{OR}=3.17$ for $<100 \% \mathrm{FPL})$. Male athletes were significantly less likely to be obese compared to male non-athletes/participants-inother-activities, except for football players. In contrast to girls, income was not significantly associated with greater odds of obesity among boys.

\section{Discussion}

The results of this study are consistent with national trends for declining levels of physical activity among adolescent youth entering high school. ${ }^{31,32}$ While an estimated 30-45 million American youth play recreational and competitive organized sports, ${ }^{33}$ nearly two-thirds of youth are estimated to withdraw from sport participation each year, with attrition rates being particularly high among adolescents..$^{20,33,34}$

Additionally, the results of this study correspond with national trends for sport participation among adolescent girls. While physical activity is important for the health of youth, ${ }^{35}$ adolescent girls reduce participation in sports more than adolescent boys in high school. ${ }^{10}$ Our analysis shows that rates of participation in the five most popular sports was $16.6 \%$ lower for girls in high school compared to middle school. One potential explanation for the drop in sport participation among adolescent girls may be related to the timing of puberty and menarche. Several studies have linked obesity in girls with earlier puberty and menarche. ${ }^{36,37}$ Prior research found that advanced pubertal girls had significantly lower self-reported PA and accumulated fewer minutes of moderate-to-vigorous and vigorous PA and accelerometer counts per day at age 13 years than girls that physically mature later. ${ }^{38}$ This may be particularly 
important for girls who are overweight or obese, as they are more likely to begin puberty earlier than their healthy-weight peers. ${ }^{39}$

However, we found virtually no differences in obesity prevalence between most common sports and non-athletes/participants-in-other-activities in girls. Our analysis does show that runners are significantly less likely to be obese than their peers who play the most popular organized female team sports. The differences in obesity rates among runners and four other organized team sport athletes are particularly important since previous research indicates that adolescent girls achieve PA primarily through sports. ${ }^{40}$

It is difficult to surmise why obesity prevalence among adolescent girls who play basketball, softball, soccer, and volleyball is similar to non-athletes/participants-in-otheractivities. One explanation may be that these sports do not provide each participant with the sufficient level of daily moderate to vigorous PA. The U.S. Department of Health and Human Services recommends children and adolescents aged 6-17 should have 60 minutes of activity or more of physical activity each day - that includes moderate or vigorous intense aerobic exercise at least three days per week. By grade 12 only $32 \%$ of females meet the recommended levels of PA, and less when using objectively measured activity. ${ }^{16,41}$ Whereas running/track can be an individual activity within an organized team, the four remaining sports examined in this study are group-based activities, which might not offer adequate levels of vigorous PA for each team member. Perhaps core team members receive significantly higher levels of moderate to vigorous PA than injured athletes or teammates who are afforded less practice or game time. Another consideration may be that females with lower BMI percentile select to participate in track rather than the four remaining popular sports. 
Compared with income and racial differences, the type of leisure time sports adolescent boys played had the strongest, most consistent inverse relationship with obesity, except for football. Consistent with other research, obesity prevalence for football players was comparable to obesity prevalence of non-athletes/participants-in-other-activities. ${ }^{42}$ The self-selection of heavier adolescents into playing football may contribute to the findings that their risk of obesity is equal to male non-athletes/participants-in-other-activities. Body composition might be another contributing factor to increased BMI rates among football players. A higher than normal BMI could potentially represent greater muscle density rather than fat. ${ }^{43}$ An examination of 71 males from different high school football player determined the use of age-adjusted BMI percentile can lead to misclassification of overweight and obese status especially for bigger lineman do to muscular body composition. ${ }^{44}$ Further studies conclude that BMI calculations from body mass and weight may not accurately portray the modern NFL athlete, Division-I NCAA, and high school football players regarding health status because BMI calculations do not distinguish between fat and lean tissue. ${ }^{45,46} \mathrm{We}$ are unaware of any existing longitudinal research or studies consisting of a larger sample size that examines the accuracy of BMI for high school aged or younger football players and our dichotomy of healthy weight vs. obese (as opposed to overweight) should help with BMI accuracy.

As expected, boys who played baseball, basketball, soccer, and running/track had significantly lower obesity. Aside from football, the obesity among male athletes is significantly lower than non-athletes/participants-in-other-activities. Similar to the female population in this study, $7 \%$ fewer boys played leisure time sport activity in high school, compared to middle school. Football and soccer participation dropped the most significantly among boys. Various reasons may account for these. The numbers of slots available to play football fall considerably 
after middle school. Researchers estimate that 3.5 million kids play football in youth leagues; that number dwindles to 1.3 million in high school. ${ }^{47}$ Boys who spent their childhood playing in soccer leagues may find other activities more appealing as teenagers. Other reasons for attrition cited by soccer players include a lack of free time and the need for more time to study. ${ }^{48}$

Consistent with studies measuring PA among adolescent females, household income was not associated with a decline in leisure time sport activity. ${ }^{10}$ As family income levels increased the girls in our study were more likely to participate in basketball, running/track, softball, and soccer. However, differences in family income did not have a significant impact on volleyball participation. Among the factors cited for influencing girls' sport participation is a lack of access, decreased quality of experience including poor facilities and non-optimal playing times, and a shortage of positive role models. Perhaps any one or all of these factors combined with other environmental issues may have a greater impact on participation rates for certain sports such as volleyball. $^{49}$

The present study proposes that household income has a greater impact on differences in female adolescent obesity than sport participation or race. Previous research suggests the prevalence of obesity among black girls was not related to household income, while the prevalence of obesity among white females was significantly higher in lowest income category than at higher income levels. ${ }^{50}$ Conversely, participation in sport participation has a bigger impact on obesity for boys than race or family income. This income paradox may be explained by school level income (schools with median incomes that are substantially lower than the national or state median incomes) or other environmental characteristics. While previous studies have shown a robust association between household income and PA, Richmond and colleagues found that after taking into account characteristics of the school that adolescent attended, 
individual household income was no longer significantly associated with adolescent PA in either males or females. ${ }^{51}$

Our data show that a greater proportion of male youth reporting leisure time sport participation are healthy weight than are female sport participants. Obesity prevalence is significantly lower among male athletes than non-athletes/participants-in-other-activities in all sports except football. We are unaware of the reasons why differences in obesity among athletes persist along gender lines. Perhaps common female sports are more accepting of different body types. Or possibly, healthy weight boys self-select to play common sports at a higher rate than their female peers. Another explanation might involve weight management. Previous research has determined that certain women do not report weight management to be significantly important for sport and exercise participation. ${ }^{52}$ It is also possible that overweight or obese girls may be encouraged to exercise more than overweight or obese boys.

Our findings do not corroborate previous reports of an association between race/ethnicity, sex, sports participation, and the prevalence of obesity. ${ }^{53}$ As expected, our results did indicate that football players and black and Hispanic males were at greater odds of being obese than their white male counter-parts who played the other popular sports, but these results were not statistically significant.

One significant limitation of these findings is that we are unable to determine if reports of sport participation were based on organized teams and leagues, or if they represent unorganized activities. It is possible that levels of PA (low, moderate, and vigorous) differ when adolescents play unstructured games with friends rather than compete in organized leagues. A second limitation is that the study relies on self-reports of PA, which suffer from significant bias. Estimating PA frequency and duration is believed to be particularly challenging for children. ${ }^{54}$ 
Also, given that with NHANES one can only examine relationships cross-sectionally, it is not clear whether weight status influences OSP or vice versa.

To our knowledge this is the first study to use multivariate analysis to examine the impact of leisure time sport activity, race, and household income on the likelihood of obesity. Our findings are that, on average, across a nationally representative sample, male and female adolescences who participate in common sports have lower rates of obesity than nonathletes/participants-in-other-activities. However, the effect of leisure time sport activity on obesity for female adolescents is not significant except for the negative relationship between obesity and running/track. These results suggest adolescent athletes who participate in the four most popular organized female team sports may benefit from increased levels of vigorous activity. Physicians who counsel parents and girls toward sport participation should recognize that while leisure time sport activity may have significant benefits, the relationship between participation and healthy weight is not as clear. Additionally, nationally represented surveys such as NHANES will benefit by collecting future data on physical activity, recreational sport participation, and organized sport participation among adolescents. 
Table 1. Demographic characteristics, by sex. P-value represents adjusted Wald test for differences in demographics by sex.

\section{Girls Boys p-value}

Total $49.8 \quad 50.2$

\begin{tabular}{|c|c|c|c|}
\hline \multicolumn{4}{|l|}{ Race/Ethnicity } \\
\hline White & 49.2 & 50.9 & 0.472 \\
\hline Black & 50.0 & 50.0 & \\
\hline Hispanic & 50.6 & 49.5 & \\
\hline Other Race & 53.8 & 46.2 & \\
\hline \multicolumn{4}{|l|}{ Income } \\
\hline$<100 \%$ & 50.4 & 49.6 & 0.835 \\
\hline $100-199 \%$ & 51.0 & 49.0 & \\
\hline $200-299 \%$ & 49.3 & 50.7 & \\
\hline $300-399 \%$ & 50.0 & 50.0 & \\
\hline $400-499 \%$ & 46.6 & 53.4 & \\
\hline$>500 \%$ & 49.3 & 50.8 & \\
\hline Missing & 52.3 & 47.7 & \\
\hline \multicolumn{4}{|l|}{ Grade } \\
\hline Middle School & 49.5 & 50.5 & 0.716 \\
\hline High School & 50.1 & 49.9 & \\
\hline \multicolumn{4}{|l|}{ Age } \\
\hline 12 & 50.0 & 50.0 & 0.277 \\
\hline 13 & 50.6 & 49.4 & \\
\hline 14 & 52.3 & 47.7 & \\
\hline 15 & 45.5 & 54.5 & \\
\hline 16 & 48.7 & 51.3 & \\
\hline 17 & 53.1 & 46.9 & \\
\hline 18 & 47.7 & 52.4 & \\
\hline 19 & 48.4 & 51.6 & \\
\hline
\end{tabular}


Table 2a. Percent of girls $(n=3345)$ playing each sport, by demographic characteristics. P-value represents adjusted Wald test for difference in participation by demographics.

\begin{tabular}{|c|c|c|c|c|c|c|c|c|c|c|c|c|}
\hline & $\begin{array}{l}\text { Non- } \\
\text { athlete/other- } \\
\text { activities }\end{array}$ & $\mathrm{P}$ & Softball & $\mathrm{P}$ & Volleyball & $\mathrm{P}$ & Basketball & $\mathrm{P}$ & Running & $\mathrm{P}$ & Soccer & $\mathrm{P}$ \\
\hline Total & 48.3 & & 4.5 & & 7.3 & & 13.0 & & 21.3 & & 5.6 & \\
\hline \multicolumn{13}{|l|}{ Race/Ethnicity } \\
\hline White & 48.1 & 0.841 & 5.9 & 0.015 & 8.7 & 0.003 & 10.4 & 0.000 & 21.4 & 0.072 & 6.4 & 0.003 \\
\hline Black & 50.0 & & 1.7 & & 4.4 & & 23.1 & & 19.8 & & 2.0 & \\
\hline \multicolumn{13}{|l|}{ Income } \\
\hline$<100 \%$ & 48.3 & 0.086 & 2.8 & 0.004 & 5.0 & 0.252 & 20.6 & 0.001 & 19.5 & 0.513 & 4.6 & 0.272 \\
\hline $100-199 \%$ & 53.9 & & 1.4 & & 6.9 & & 14.6 & & 18.8 & & 5.5 & \\
\hline $200-299 \%$ & 45.4 & & 6.2 & & 9.3 & & 11.0 & & 24.4 & & 4.1 & \\
\hline $300-399 \%$ & 47.7 & & 5.2 & & 8.3 & & 9.4 & & 24.4 & & 6.7 & \\
\hline \multicolumn{13}{|l|}{ Grade } \\
\hline Middle School & 40.4 & 0.000 & 6.2 & 0.001 & 8.4 & 0.056 & 17.7 & 0.000 & 21.4 & 0.767 & 6.8 & 0.050 \\
\hline High School & 56.7 & & 2.8 & & 6.1 & & 8.4 & & 22.0 & & 4.7 & \\
\hline
\end{tabular}


Table 2b. Percent of boys $(n=3330)$ playing each sport, by demographic characteristics. P-value represents adjusted Wald test for difference in participation by demographics.

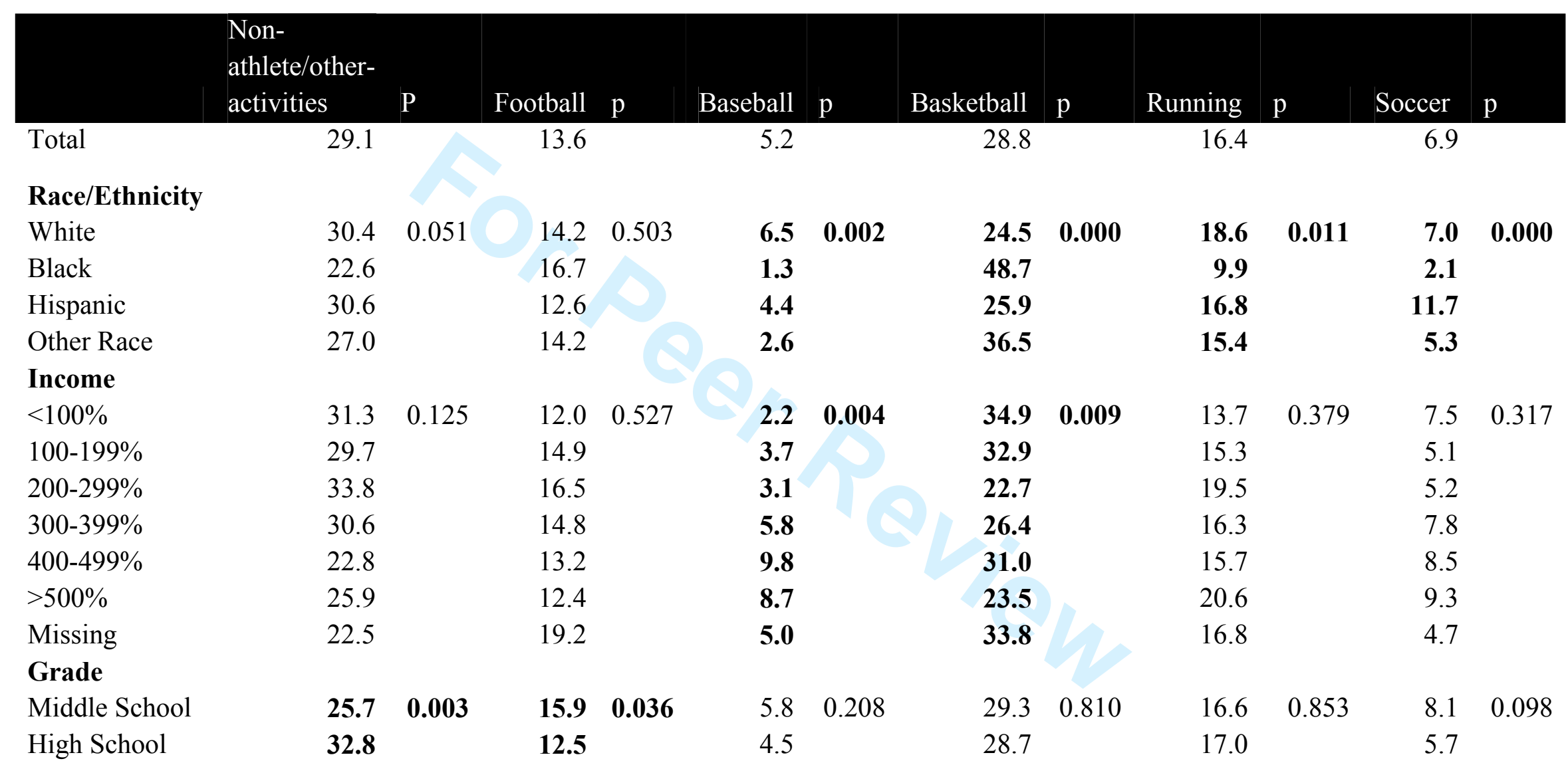


Table 3. Percent of girls and boys who are obese (BMI $>95^{\text {th }}$ percentile), by sport. P-value represents adjusted Wald test comparing each sport to the population playing no sport/participant-in-other-activities.

\begin{tabular}{lcccc} 
& Girls & $\mathrm{p}$ & Boys & $\mathrm{p}$ \\
\hline $\begin{array}{l}\text { Any Sports } \\
\text { Non-athlete/participant-in- }\end{array}$ & 15.3 & 0.210 & $\mathbf{1 6 . 6}$ & $\mathbf{0 . 0 0 0}$ \\
other activities & & & & \\
Football & 17.0 & & $\mathbf{2 3 . 6}$ & \\
Baseball & & & 24.5 & 0.756 \\
Basketball & & & $\mathbf{1 1 . 3}$ & $\mathbf{0 . 0 0 6}$ \\
Running & 16.8 & 0.922 & $\mathbf{1 6 . 5}$ & $\mathbf{0 . 0 0 2}$ \\
Soccer & $\mathbf{1 1 . 2}$ & $\mathbf{0 . 0 0 1}$ & $\mathbf{1 5 . 9}$ & $\mathbf{0 . 0 0 6}$ \\
Softball & 20.0 & 0.565 & $\mathbf{7 . 2}$ & $\mathbf{0 . 0 0 0}$ \\
Volleyball & 19.0 & 0.654 & & \\
& 20.9 & 0.208 & &
\end{tabular}


Table 4. Logistic regression of the effect of sports on the likelihood of being obese.

\begin{tabular}{|c|c|c|c|c|c|c|c|c|}
\hline & Girls & & & \multicolumn{2}{|c|}{ Boys } & \multirow[b]{2}{*}{ CI } & & \multirow[b]{2}{*}{$\mathrm{p}$} \\
\hline & OR & $\mathrm{CI}$ & & $\mathrm{p}$ & OR & & & \\
\hline Football & - & & - & - & 1.12 & {$[0.80$} & $-1.57]$ & 0.487 \\
\hline Baseball & - & & - & - & 0.46 & {$[0.24$} & -0.88 & 0.020 \\
\hline Basketball & 0.83 & {$[0.60$} & $-1.14]$ & 0.233 & 0.67 & {$[0.50$} & $-0.90]$ & 0.008 \\
\hline Running & 0.62 & {$[0.46$} & $-0.83]$ & 0.002 & 0.65 & {$[0.46$} & $-0.92]$ & 0.016 \\
\hline Soccer & 1.35 & {$[0.67$} & $-2.72]$ & 0.393 & 0.25 & {$[0.14$} & $-0.45]$ & 0.000 \\
\hline Softball & 1.24 & {$[0.70$} & $-2.19]$ & 0.457 & & & - & - \\
\hline Volleyball & 1.38 & {$[0.87$} & $-2.19]$ & 0.169 & & & - & - \\
\hline High & & & & & & & & \\
\hline School & 0.68 & {$[0.51$} & $-0.90]$ & 0.008 & 1.05 & {$[0.76$} & $-1.44]$ & 0.770 \\
\hline Black & 2.06 & {$[1.50$} & $-2.83]$ & 0.000 & 1.10 & {$[0.87$} & $-1.40]$ & 0.419 \\
\hline Hispanic & 1.43 & {$[0.97$} & $-2.10]$ & 0.072 & 1.55 & {$[1.22$} & $-1.98]$ & 0.001 \\
\hline Other Race & 0.88 & {$[0.48$} & $-1.60]$ & 0.660 & 0.77 & {$[0.41$} & $-1.44]$ & 0.409 \\
\hline$<100 \%$ & 3.17 & [1.63 & $-6.16]$ & 0.001 & 1.42 & {$[0.90$} & $-2.23]$ & 0.131 \\
\hline $100-199 \%$ & 2.27 & {$[1.22$} & $-4.24]$ & 0.011 & 1.16 & {$[0.69$} & $-1.93]$ & 0.576 \\
\hline $200-299 \%$ & 2.99 & {$[1.59$} & $-5.61]$ & 0.001 & 1.44 & {$[0.86$} & $-2.41]$ & 0.159 \\
\hline $300-399 \%$ & 2.85 & [1.47 & $-5.52]$ & 0.002 & 1.28 & {$[0.80$} & $-2.04]$ & 0.296 \\
\hline $400-499 \%$ & 2.34 & {$[0.99$} & $-5.55]$ & 0.053 & 1.09 & {$[0.63$} & $-1.89]$ & 0.745 \\
\hline Missing & 2.67 & [1.19 & $-6.03]$ & 0.019 & 1.42 & {$[0.71$} & $-2.86]$ & 0.315 \\
\hline Constant & 0.08 & {$[0.04$} & $-0.16]$ & 0.000 & 0.21 & {$[0.13$} & $-0.36]$ & 0.000 \\
\hline
\end{tabular}




\section{References}

1. Ogden CL, Carroll MD, Kit BK, Flegal KM. Prevalence of obesity and trends in body mass index among US children and adolescents, 1999-2010. JAMA : the journal of the American Medical Association. Feb 1 2012;307(5):483-490.

2. Dietz WH, Gortmaker SL. Preventing obesity in children and adolescents. Annu Rev Public Health. 2001;22:337-353.

3. Troiano RP, Berrigan D, Dodd KW, Masse LC, Tilert T, Mcdowell M. Physical activity in the United States measured by accelerometer. Medicine and science in sports and exercise. Jan 2008;40(1):181-188.

4. Gordon-Larsen P, McMurray RG, Popkin BM. Determinants of adolescent physical activity and inactivity patterns. Pediatrics. Jun 2000;105(6):E83.

5. Trost SG, Pate RR, Sallis JF, et al. Age and gender differences in objectively measured physical activity in youth. Medicine and science in sports and exercise. Feb 2002;34(2):350-355.

6. Sallis JF, Prochaska JJ, Taylor WC. A review of correlates of physical activity of children and adolescents. Medicine and science in sports and exercise. May 2000;32(5):963-975.

7. Nader PR, Bradley RH, Houts RM, McRitchie SL, O'Brien M. Moderate-to-vigorous physical activity from ages 9 to 15 years. Jama. Jul 16 2008;300(3):295-305.

8. Perkins DF, Jocobs JE, Barber BL, Eccles JS. Childhood and adolescent sports participation as predicators of participation in sports and physical fitness activities during young adulthood. Youth Soc. Jun 2004;35(4):495-520.

9. Gordon-Larsen P, Adair LS, Popkin BM. Ethnic differences in physical activity and inactivity patterns and overweight status. Obes Res. Mar 2002;10(3):141-149.

10. Kimm SY, Glynn NW, Kriska AM, et al. Decline in physical activity in black girls and white girls during adolescence. The New England journal of medicine. Sep 5 2002;347(10):709715.

11. Kirshnit CE, Ham M, Richards $\mathrm{MH}$. The sporting life: Athletic activities during early adolescence. J Youth Adolesc. Dec 1989;18(6):601-615.

12. Pfeiffer KA, Dowda M, Dishman RK, et al. Sport participation and physical activity in adolescent females across a four-year period. J Adolesc Health. Oct 2006;39(4):523-529.

13. Jago R, Baranowski T. Non-curricular approaches for increasing physical activity in youth: a review. Preventive medicine. 2004;39(1):157-163.

14. Wimer C, Bouffard SM, Caronongan P, et al. What Are Kids Getting into These Days? Demographic Differences in Youth Out-of School Time Participation. Harvard Family Research Project, Harvard University. 2006.

15. Casper JM, Bocarro JN, Kanters MA, Floyd MF. "Just let me play!" - understanding constraints that limit adolescent sport participation. J Phys Act Health. Jan 2011;8 Suppl 1:S32-39.

16. Chung AE, Skinner AC, Steiner MJ, Perrin EM. Physical activity and BMI in a nationally representative sample of children and adolescents. Clinical Pediatrics. Feb 2012;51(2):122-129.

17. Gordon-Larsen P, Nelson MC, Page P, Popkin BM. Inequality in the built environment underlies key health disparities in physical activity and obesity. Pediatrics. Feb 2006;117(2):417-424. 
18. Harrison PA, Narayan G. Differences in behavior, psychological factors, and environmental factors associated with participation in school sports and other activities in adolescence. The Journal of school health. Mar 2003;73(3):113-120.

19. Marsh HW, Kleitman S. School athletic participation: Mostly gain with little pain. J Sport Exercise Psy. Jun 2003;25(2):205-228.

20. Mcneal RB. Extracurricular Activities and High-School Dropouts. Sociol Educ. Jan 1995;68(1):62-80.

21. Sallis JF, Alcaraz JE, McKenzie TL, Hovell MF. Predictors of change in children's physical activity over 20 months: variations by gender and level of adiposity. American journal of preventive medicine. 1999;16(3):222-229.

22. Olds TS, Ferrar KE, Schranz NK, Maher CA. Obese adolescents are less active than their normal-weight peers, but wherein lies the difference? J Adolescent Health. 2011;48(2):189-195.

23. Bar-Or O, IOC Medical Commission., International Federation of Sports Medicine. The child and adolescent athlete. Oxford ; Cambridge, Mass., USA

Champaign, III.: Blackwell Science ;

Distributors, Human Kinetics Books; 1996.

24. Fraser-Thomas J, Cote J, Deakin J. Understanding dropout and prolonged engagement in adolescent competitive sport. Psychol Sport Exerc. Sep 2008;9(5):645-662.

25. National Center for Health Statistics. NHANES General Data Release Documentation. 2008; http://www.cdc.gov/nchs/nhanes/nhanes2007-2008/generaldoc e.htm.

26. National Center for Health Statistics. National Health and Nutrition Examination Survey: 1999-2010 Survey Contents. 2010; http://www.cdc.gov/nchs/data/nhanes/survey content 99 10.pdf.

27. National Federation of State High School Associations. 2011-2012 High School Athletic Participation Survey. Indianapolis, IN2013.

28. Barlow SE, Expert C. Expert committee recommendations regarding the prevention, assessment, and treatment of child and adolescent overweight and obesity: summary report. Pediatrics. 2007;120 Suppl 4(Journal Article):S164-192.

29. National Center for Chronic Disease Prevention and Health Promotion, Centers for Disease Control and Prevention. A SAS Program for the CDC Growth Charts. [Web site]. 2005; http://www.cdc.gov/nccdphp/dnpa/growthcharts/sas.htm. Accessed December 7, 2005, 2005.

30. Nelson TF, Stovitz SD, Thomas M, Lavoi NM, Bauer KW, Neumark-Sztainer D. Do Youth Sports Prevent Pediatric Obesity? A Systematic Review and Commentary. Curr Sports Med Rep. Nov-Dec 2011;10(6):360-370.

31. Dumith SC, Gigante DP, Domingues MR, Kohl HW, 3rd. Physical activity change during adolescence: a systematic review and a pooled analysis. Int J Epidemiol. Jun 2011;40(3):685-698.

32. Bradley RH, McRitchie S, Houts RM, Nader P, O'Brien M, Network NECCR. Parenting and the decline of physical activity from age 9 to 15. The international journal of behavioral nutrition and physical activity. 2011;8:33.

33. Indiana University. Why Kids Ditch Youth Sports. August 15, 2006; http://newsinfo.iu.edu/web/page/print/3885.html. Accessed February 18, 2013.

34. Hedstrom R, Gould D. Research in Youth Sports: Critical Issues Status. Lansing, MI: Institute for the Study of Youth Sports, Michigan State University;2004. 
35. Strong WB, Malina RM, Blimkie CJR, et al. Evidence based physical activity for school-age youth. J Pediatr-Us. Jun 2005;146(6):732-737.

36. Freedman DS, Khan LK, Serdula MK, Galuska DA, Dietz WH. Trends and correlates of class 3 obesity in the United States from 1990 through 2000. Jama. Oct 9 2002;288(14):1758-1761.

37. Biro FM, McMahon RP, Striegel-Moore R, et al. Impact of timing of pubertal maturation on growth in black and white female adolescents: The National Heart, Lung, and Blood Institute Growth and Health Study. J Pediatr. May 2001;138(5):636-643.

38. Baker BL, Birch LL, Trost SG, Davison KK. Advanced pubertal status at age 11 and lower physical activity in adolescent girls. J Pediatr-Us. Nov 2007;151(5):488-493.

39. Walvoord EC. The timing of puberty: is it changing? Does it matter? The Journal of adolescent health : official publication of the Society for Adolescent Medicine. Nov 2010;47(5):433-439.

40. Pfeiffer KA, Dowda M, Dishman RK, et al. Sport participation and physical activity in adolescent females across a four-year period. The Journal of adolescent health : official publication of the Society for Adolescent Medicine. Oct 2006;39(4):523-529.

41. Eaton DK, Kann L, Kinchen S, et al. Youth risk behavior surveillance - United States, 2011. MMWR Surveill Summ. Jun 8 2012;61(4):1-162.

42. Elkins WL, Cohen DA, Koralewicz LM, Taylor SN. After school activities, overweight, and obesity among inner city youth. J Adolesc. Apr 2004;27(2):181-189.

43. Mingrone $G$, Marino S, DeGaetano A, et al. Different limit to the body's ability of increasing fat-free mass. Metabolism: clinical and experimental. Sep 2001;50(9):10041007.

44. American College of Sports Medicine. Body Mass Index Unreliable Measure of High School Footballers. 2011; http://www.acsm.org/about-acsm/media-room/acsm-in-thenews/2011/08/01/body-mass-index-unreliable-measure-of-high-school-footballers. Accessed September 5, 2014.

45. Kraemer WJ, Torine JC, Silvestre R, et al. Body size and composition of national football league players. Journal of Strength and Conditioning Research. Aug 2005;19(3):485-489.

46. Repovich WE, Babcock GJ. Division IAA Football Players and Risk Factors for Metabolic Syndrome. ICHPER-SD Journal of Research. 2012;7(1):34-39.

47. Daniel RW, Rowson S, Duma SM. Head Impact Exposure in Youth Football. Ann Biomed Eng. Apr 2012;40(4):976-981.

48. DuRant RH, Pendergrast RA, Donner J, Seymore C, Gaillard G. Adolescents' attrition from school-sponsored sports. American journal of diseases of children. Oct 1991;145(10):1119-1123.

49. Staurowsky EJ, Miller KE, Shakib S, et al. Her Life Depends on It II: Sport, Physical Activity, and the Health and Well-Being of American Girls and Women. Women's Sports Foundation. 2009.

50. Patterson ML, Stern S, Crawford PB, et al. Sociodemographic factors and obesity in preadolescent black and white girls: NHLBI's Growth and Health Study. Journal of the National Medical Association. Sep 1997;89(9):594-600.

51. Richmond TK, Hayward RA, Gahagan S, Field AE, Heisler M. Can school income and racial/ethnic composition explain the racial/ethnic disparity in adolescent physical activity participation? Pediatrics. Jun 2006;117(6):2158-2166.

52. Koivula N. Sport participation: Differences in motivation and actual participation due to gender typing. Journal of Sport Behavior. 1999. 
53. Delva J, O'Malley PM, Johnston LD. Racial/ethnic and socioeconomic status differences in overweight and health-related behaviors among American students: national trends 1986-2003. The Journal of adolescent health : official publication of the Society for Adolescent Medicine. Oct 2006;39(4):536-545.

54. Sallis JF, Saelens BE. Assessment of physical activity by self-report: Status, limitations, and future directions. Res Q Exercise Sport. Jun 2000;71(2):S1-S14. 